\title{
Assessment of the current status of adoption of Six Sigma by auto components sector - Literature Review
}

\author{
A Raghunath*' Dr. R V Jayathirtha* \\ "Research Scholar, Centre for Research, Anna University of Technology, Coimbatore, India \\ *.* Director, Bullseye Consulting Group, Bangalore, India
}

\begin{abstract}
Six Sigma is a business improvement strategy that focuses on improving products, processes and bottom line of businesses. The ultimate goal of Six Sigma is flawless performance leading to remarkable and tangible quality improvements when implemented judiciously. An attempt has been made to review all the available literature about the current researches and empirical studies regarding the adoption of Six Sigma by companies and findings of most of the implementation efforts are presented in this article.

Keywords: Six Sigma, survey, implementation, auto components, automotive sector, manufacturing industry
\end{abstract}

\section{Introduction}

In the present ever changing and highly competitive environment it is imperative that the companies continuously improve themselves for survival and growth. Quality and cost are the two key elements for the success of any manufacturing industry. Industries are adopting different systems such as ISO 9000, TQM, etc. to improve quality. But, these systems failed to bring in the financial element of the businesses into focus. Six Sigma is a business improvement initiative rather than a quality initiative. It is a customer focused business improvement methodology driven by data than assumptions with breakthrough performance gains validated by bottom line results. It enables an organization to improve performance by eliminating deficient processes and defects in products and services. The companies that adopt Six Sigma approach will have to reduce the process variation so drastically that the number of defective parts will come down to negligible level. If a company is at 3 sigma level the number of rejections per million would be around 67000 and with the adoption of six sigma the rejections would be as less as only 3.4 PPM. Six Sigma project management approach will change the culture of the companies in many ways. Originally goal of Six Sigma was to focus on manufacturing processes and was confined to the domain of only the large OEM companies. However, Six Sigma approach applies equally well to the delivery of services as it does to the manufacture of products and Six Sigma concepts, methods and the tools are equally applicable for small and medium enterprises as for large companies. In general, Six Sigma is applicable for any company of any size delivering any product or service to the customers. It is very vital for the auto component manufacturing sector to employ Six Sigma methodologies for defects free production and be globally cost effective. This literature review was carried out as a prelude to the research on effectiveness of implementation of Six Sigma by auto-component manufacturing industries. The present paper is focused on the literature review on implementation of Six Sigma by manufacturing and service companies at a broader spectrum considering findings related to various inter related factors like: benefits of implementation; barriers for implementation; critical success factors; metrics for measurement of break through performance; customer satisfaction; change in organization culture; leadership behaviour; change management; etc.

\section{Review of the literature}

Jiju Antony (Ref. 5) presents the results of a pilot survey of the service organizations based in the UK to understand status of Six Sigma. The paper reports the essential ingredients that are required for the successful deployment of Six Sigma in the service sector. According to the authors, service-oriented businesses adopting Six Sigma business strategy have the benefits like: Improved cross-functional teamwork across the entire organization; transformation of organizational culture from reactive mode to preventive mode; Increased employee morale; reduced number of non-value added steps in critical business processes leading to faster delivery of service and reduced throughput time; reduced cost of poor quality (COPQ) (costs associated with late delivery, customer complaints, repair and rework etc.); increased awareness of various problem solving tools and techniques, leading to greater job satisfaction for employees; improved consistency level of service through systematic reduction of variability in processes; and effective management decisions due to reliance on data and facts rather than assumptions. The criteria considered during the project selection process are: impact on customer needs and expectations; financial impact on the bottom-line; duration of the projects considered; resources required for projects under consideration; expertise and skills required to carry out the projects; probability of success of projects under consideration and risk involved in projects, etc. The guidelines given by the authors that may be used to select Six Sigma projects are: projects should have linkage to strategic business 
plan and organizational goals; projects should improve the overall business performance both financially and service process vise; projects should be doable in less than six months; The time for completion and hence the cost of the project deployment will increase if broader scope is assigned to the project. This would lead to frustration among the key players due to lack of progress, diversion of manpower, delay in realization of financial benefits, etc.; Project objectives must be clear, succinct, specific, achievable, realistic and measurable (SMART). Projects should have the support and approval of the senior management. Project deliverables should be defined in terms of their impact on one or more critical characteristics in the service such as CTQ, critical-tocost or critical-to-delivery. Projects must be selected based on realistic and good metrics (DPMO, SQL, Capability Indices, etc.).

Pulaknam \& Voges (Ref. 11) have reviewed seventeen studies, which the authors believed constitute most of the published empirical studies on implementing Six Sigma in different parts of the world. Nine of these were research journal articles and the others included a $\mathrm{PhD}$ thesis and research reports published by research, consulting or professional organizations such as Aberdeen Group, IW/MPI (Industry Week / Manufacturing Performance Institute), EIU (Economic Intelligence Unit) and CC (Celerant Consulting). These empirical studies on Six Sigma were undertaken in UK, USA, Canada, India, Brazil, Singapore, and Taiwan. Empirical studies covered all sectors of industries including healthcare, financial institutions, information technology as well as the SME sector. The authors are of the opinion that despite the apparent popularity of Six Sigma, very little is known about the extent to which Six Sigma has actually been adopted by business firms in the world, the patterns of adoption across industrial sectors and occupational groups, and the factors that differentiate firms that heavily adopt Six Sigma from those who do not. As per the authors, a number of empirical studies have been undertaken in different countries and industry sectors to address these gaps and the majority of those studies are reviewed. The review includes the extent of Six Sigma adoption in industry, and the benefits and major hurdles in implementing the programme. This research paper concludes with a brief review of methodological limitations in those studies and how future research can address them.

Lee Revere, Sukran N, Kadipasaoglu \& Faiza Zalila (Ref. 6), USA have published a research paper on pilot research exploring the critical success factors of Six Sigma. It gives insight into the gaps between Six Sigma theory and execution and the primary drivers of financial improvements. Findings of the authors demonstrate the key aspects that seem to be consistent among Six Sigma organizations. According to the authors organizations cite Six Sigma for cost reduction and increased revenues. Chi-square analyses indicate gaps exist between theory and actual practice across the three critical success factors viz. team selection, project selection and project implementation. A larger percent of respondents agree on the criticality of key tasks/issues, yet fewer companies execute them in practice. Regression results demonstrate that the factors like team selection and project selection significantly impact the financial performance of the organizations.

Xingxing Zu, Lawrence D Fredendall \& Tina L Robbins (Ref. 12) have done a study for understanding the effect of organizational culture on Six Sigma by empirically investigating the relationship between culture and quality practices associated with Six Sigma implementation in US manufacturing companies. The authors have reviewed both the academic and practitioner literature to identify key quality practices in Six Sigma. According to the authors while industry is increasingly adopting Six Sigma, there is very little academic research on Six Sigma practices and much of the Six Sigma literature is written by practitioners who worked in major companies that used Six Sigma including GE, Motorola, Honeywell, etc. Literature review of the authors encompass key practices like top management support, customer relationship, supplier relationship, workforce management, quality information, product/service design, process management, six sigma role structure, structured improvement procedure and focus on metrics. Study of these authors is an effort to conduct a comprehensive assessment of the relationships between different cultural orientations and quality practices in Six Sigma. The findings suggest that organizational culture generally has a significant influence on quality management and different cultural orientations influence different quality practices. The authors argue that Six Sigma is multidimensional consisting of multiple quality management practices, which are driven by and reflect multiple dimensions of organizational culture. It appears that not only emphasis on the flexibility and peopleoriented cultural orientations (i.e., group and developmental culture) but also emphasis on the control-oriented cultural orientation (i.e., rational culture) can lead to higher implementation level of quality practices.

Darshak A. Desai (Ref. 1) illustrates the results obtained from a cross-sectional study of the benefits obtained by entire Indian industries as a whole by implementing Six Sigma in their organizations. The basic objective of the research study was to highlight the spectrum of benefits the Indian industries could achieve by Six Sigma and thus to encourage other industries who have not yet attempted Six Sigma for the breakthrough improvements. According to the author sparing some sporadic articles and case studies in the corporate publications and magazines, the research publications illustrating wide-ranging studies regarding penetration of Six Sigma among Indian industries as a whole are not available so far. The author lists the challenges and advantages of SSI sectors on Six Sigma initiatives compared to large organizations. The challenges listed by the author are: lack of time and resources for implementing the drive; ignorance about the strategic gains of Six 
Sigma; misconception that Six Sigma involves a lot of statistics and it is a sort of luxury; comfortable with tradition of resorting to quick-fix solutions; solving the problems as and when they encounter; indifferent attitude about investing time and money in the long term, permanent and strategic solutions. The advantages listed by the author are: complete involvement of top management in the implementation drive; ease of arriving at the consensus for the most problematic area for initial trial of Six Sigma improvement drive; convenience of keeping a close watch on the processes and experimenting with variables; easier and faster response to the change management program in the context of Six Sigma implementation. According to the author the benefits of small size are: speed and flexibility in responding to change; ease of keeping close to the customers and locating the vital few Critical to Quality (CTQs) parameters. The following points have been listed as the answer to why many industries are apathetic about Six Sigma (Edgeman and Bigio, 2004): they think that their existing culture and system, such as ISO 9000 and continuous improvement are sufficient to meet their needs; they think that the managerial benefit to the organisation of adopting Six Sigma does not justify its cost; they lack knowledge of Six Sigma or the internal capability to assess its potential value to their organization; they have a perception that the cost of hiring, training and retaining Six Sigma talents is prohibitive compared to the returns.

Prof. Dr. Armin Töpfer (Ref. 10) in his paper "Six Sigma - Project management for zero defect quality in the automobile industry" states that Six Sigma is a perfect solution if introduced in its entirety and applied consistently, if the company managers and directors provide their full commitment and if there is a company culture which encourages transparency of errors, stringent project control and a desire for quantitative results. According to the author automobile manufacturers have recognized this and demand zero defect quality from their suppliers. The author opines that companies who develop high level of Six Sigma expertise at an early stage will achieve significant cost reductions and gain competitive advantages. The author's suggestion of seven elements or stages for introducing a Six Sigma project are: understanding the project-oriented specific directions or requirements and performance capability of six sigma; involvement of the company management and commitment of the directors; structuring the Six Sigma groups and recruiting /selecting the right players; qualifying Six Sigma specialists (Champions, Master Black Belts, Black Belts, Green Belts and Yellow Belts); selecting suitable Six Sigma projects; analysis of the financial consequences of Six Sigma; introduction of project control and creation of a knowledge management concept.

G.V. Prabhushankar, S R Devadasan \& P R Shalij (Ref. 8) have conducted a research by interviewing the practitioners of automobile components manufacturing companies located in Bangalore city. The authors' aim was to assess the trend in implementing Quality Management System (QMS) standards, Six Sigma programme and innovation practice in Indian automobile components manufacturing sector. The overall assessment of the authors was that the conglomeration of these three strategies to bring out synergy out of them was missing. The authors stress on the need for exclusive model of QMS which would link the standards, innovation practices and Six Sigma for enabling the automobile manufacturing sector of not only India, but also of other developing countries to achieve world class competitiveness.

Jiju Antony \& Darshak A. Desai (Ref. 4), have presented results from an exploratory study conducted within the Indian state of Gujarat. According to the authors although many Indian industries have successfully embraced the six-sigma business improvement strategy, the adoption of Six Sigma in Indian industries is not as encouraging as it should be. In the research paper the authors have examined the status of six sigma implementation in Indian industries including the details, such as how long companies have been using six sigma, their implementation process, the tools and techniques that have been employed and common six sigma metrics used by Indian companies. The paper also identifies the critical success factors (CSFs) for six-sigma implementation in the Indian industries, followed by the key benefits derived from six-sigma implementation and the common barriers encountered.

Rajeshkumar U. Sambhe \&; Dr. Rajendra S Dalu (Ref. 9) have presented a paper on "Evaluation of Critical Success Factors For Successful Six Sigma Implementation in Indian Medium Scale Automotive Enterprises" with the objective of the research as to study the implementation of Six Sigma in Indian mid- sized automotive organizations, identification and analysis of critical success factors and development of Six Sigma framework. The survey reported was conducted from December 2009 to July 2010 and restricted to medium scale automotive industries located in and around Pune city of India. Fifteen critical success factors for Six Sigma Implementation were considered for their research. Based on evaluation of the results of the survey, the authors have grouped the critical factors for successful implementation of Six Sigma in to four categories with the following number of factors under them: most critical - two, next level critical - eight, lower end critical four and least critical - one. According to the authors the two most critical success factors are: an effective top management leadership and Commitment; and team selection for Six Sigma projects. The least critical factor for successful implementation of Six Sigma as per the finding of the authors is the role of information technology. 


\section{References}

[1] Darshak A Desai: Improving customer delivery commitments the Six Sigma way: case study of an Indian small scale industry, 'Int. J. Six Sigma and Competitive Advantage', vol. 2, no. 1, 2006

[2] Darshak A Desai; Mulchand B Patel: Impact of Six Sigma in a developing economy: analysis on benefits drawn by Indian industries, 'Journal of Industrial Engineering and Management', vol. 2, no. 3, 2009, 517-538

[3] Edgeman, RL; Bigio, DL: Six Sigma in Metaphor: heresy or holy writ?, 'Quality Progess', January 2004, 25-30

[4] Jiju Antony; Darshak A Desai; Assessing the status of six sigma implementation in the Indian industry, Results from an exploratory empirical study, 'Management Research News', vol. 32, no. 5, 2009, 413-423

[5] Jiju Antony: Six Sigma in the UK service organisations: results from a pilot survey, 'Managerial Auditing Journal', vol. 19, no. 8, 2004, 1006-1013

[6] Lee Revere; Sukran, N; Kadipasaoglu; Faiza Zalila: An empirical investigation into Six Sigma critical success factors, 'Int. J. of Productivity and Quality Management', vol 1, no. 3, 2006, 224-252

[7] Paulo A Cauchick Miguel, (1, 2); João Marcos Andrietta, (2): An Exploratory-descriptive Survey on Six Sigma Utilisation in Brazil, 1. Universidade de São Paulo - USP, Brazil, 2. Universidade Metodista de Piracicaba - UNIMEP, Brazil

[8] Prabhushankar, GV; Devadasan, SR; Shalij, PR: Journey of Indian automobile components sector: from Quality Management System certification to innovation via Six Sigma, 'International Journal of Indian Culture and Business Management', vol 2, no. 2, 2009, 185-210

[9] Rajeshkumar U Sambhe; Dr. Rajendra S Dalu: Evaluation of Critical Success Factors For Successful Six Sigma Implementation in Indian Medium Scale Automotive Enterprises, 'International Journal of Engineering Science and Technology (IJEST)', vol. 3, no. 3, Mar 2011

[10] Töpfer Armin: Six Sigma - Project management for zero defect quality in the automobile industry, 'www.slideshare.net/Sixsigmacentral/six-sigma-project-m... - United States', 16 Apr 2010

[11] Venkateswarlu Pulakanam; Kevin E Voges: Adoption of Six Sigma: Review of Empirical Research, 'International Review of Business Research Papers', vol. 6, no. 5, November 2010, 149 - 163

[12] Xingxing Zu; Lawrence D Fredendall; Tina L Robbins: Organizational Culture and Quality Practices in Six Sigma, 'The 2006 Annual Meeting of the Academy of Management', June 2006

[13] Jim Folaron; J P Morgan: The Evolution of Six Sigma, 'Six Sigma Forum Magazine', August 2003, www.asq.org

[14] James M Lucas: The Essential Six Sigma - How successful Six Sigma implementation can improve the bottom line, 'Quality Progress', January 2002, www.asq.org

[15] Mark Goldstein: Six Sigma Program Success Factors, 'Six Sigma Forum Magazine', November 2001, www.asq.org

[16] 'India Symposium, IBEF', Sectoral Reports - Automotive, Davos, 2006 